Sharif University of Technology
Scientia Iranica
Transactions E: Industrial Engineering
h.te://scientiairanica.sharif.edu
IRAN ICA

\title{
An imperfect multi-item single-machine production system with shortage, rework, and scrap considering inspection, dissimilar deficiency levels, and non-zero setup times
}

\author{
A.H. Nobil ${ }^{\mathrm{a}}$, A.H. Afshar Sedigh ${ }^{\mathrm{b}}$, S. Tiwari ${ }^{\mathrm{c}}$, and H.M. Wee ${ }^{\mathrm{d}, *}$ \\ a. Faculty of Industrial and Mechanical Engineering, Qazvin Branch, Islamic Azad University, Qazvin, Iran. \\ b. Information Science, University of Otago, Dunedin, New Zealand. \\ c. The Logistics Institute-Asia Pacific, National University of Singapore, 21 Heng Mui Keng Terrace, \#04-01, Singapore 119613. \\ d. Department of Industrial and Systems Engineering, Chung Yuan Christian University, No. 200, Chung Pei Road, Chung Li \\ District, Taoyuan City, 32023, Taiwan.
}

Received 11 August 2017; received in revised form 8 November 2017; accepted 1 January 2018

\section{KEYWORDS \\ Lot sizing; \\ Imperfect \\ manufacturing; \\ Multiple rework; \\ Single machine; \\ Exact algorithm.}

\begin{abstract}
In this paper, we consider a deficient production system with permissible shortages. The production system consists in a unique machine that manufactures a number of products with a part being imperfect in the form of rework or scrap. These defective products are identified by $100 \%$ inspection during production; then, they are whether reworked or disposed of after normal production process. Like real-world production systems, there are diverse types of errors creating dissimilar breakdown severity and rework. Moreover, rework has non-zero setup time, which makes the problem closer to real-world instances, and the machines require some preparations before starting a new production cycle. Thus, we introduce an Economic Production Quantity (EPQ) problem for an imperfect manufacturing system with non-zero setup times for rework items. The rework items are classified into several categories based on their types of failure and rework rates. The aim of this study is to obtain optimum production time and shortage in each period minimizing total inventory system costs. Convexity of the objective function and exact solution procedure for the current nonlinear optimization problem are also proposed. Finally, a numerical example is presented to assess efficiency and validity of the proposed algorithm. (C) 2019 Sharif University of Technology. All rights reserved.
\end{abstract}

\section{Introduction}

For any manufacturing organization, supply chain, inventory, and production management is vital to achieve success. In attaining the objectives of operation

*. Corresponding author.

E-mail addresses: amirhossein.nobil@yahoo.com (A.H. Nobil); amir.afshar@postgrad.otago.ac.nz (A.H. Afshar Sedigh); sunil.tiwari047@gmail.com (S. Tiwari); weehm@cycu.edu.tw (H.M.Wee).

doi: $10.24200 /$ sci. 2018.4984 .1031 management, each company should effectively utilize resources and try to minimize costs as much as possible. In today's competitive environment, every organization wants to make sure that their customers are satisfied with the quality of their products. On the other hand, no customer wants to compromise on the quality of the product. In the classic EPQ model, it is assumed that during a production run, $100 \%$ perfect products are manufactured, which is far from the reality. There are so many reasons for which a smaller percent the items produced will be imperfect, e.g., situations such as breakdown of the machine, interruption in 
manufacturing process, etc. Therefore, one cannot ignore the issue of imperfect production as it has direct side effects on the reputation and good-will of the organization. Employing mathematical optimizations for inventory management dates back to more than a century ago when Ford Whitman Harris introduced classical Economic Order Quantity (EOQ) inventory model in 1913 [1]. This model is the foundation of lot-sizing models and one can consider Harris as the founder of the modern inventory studies [2].

In 1918, Taft [3] proposed Economic Production Quantity (EPQ) by extending the aforementioned inventory model to a manufacturer that produced an item at a constant rate. The main drawback of such inventory models is their impractical assumptions. Therefore, several studies have relaxed these assumptions to make the models more applicable to realworld instances. For example, Hadley and Whitin [4] presented a summary of the EOQ inventory model and extended this model by taking shortage into account. Moreover, Parker [5] investigated reorder point and reorder quantities for an inventory system with stochastic demand and permissible backorder. On the other hand, Yao and Lee [6], Lee and Yao [7], and Björk [8] among others developed the EOQ model for instances of employing fuzzy numbers to approximate model parameters. Moreover, Silver [9], Maddah and Jaber [10], and Khan et al. [11] considered stochastic uncertainties in parameters under several assumptions.

Flawless products and perfect quality is another impractical assumption in the basic EOQ/EPQ inventory models. In organizations of the modern world, deteriorating items have drawn attention in different forms, i.e., scrapped, defective, reworked, obsolescent, etc. One of the first instances of inventory models with deteriorating items was proposed by Whitin [12], in which items became obsolete by time. Aggarwal and Jaggi [13] studied permissible delay in payments with deteriorating products. Wu et al. [14] studied an inventory system consisting in non-instantaneous deteriorating items with partial backordering. Chang et al. [15] developed the aforementioned model by maximizing total profit, instead of minimizing cost per time unit, considering maximum inventory level constraint. Wu et al. [16] addressed deteriorating items with expiration dates and trade credit when trade credit increased revenue as well as opportunity cost and default risk. Some recent studies that have investigated inventory management with deteriorating items under different policies are Sett et al. [17], Wu and Zhao [18], Mokhtari et al. [19], Wu et al. [20], Shah and CárdenasBarrón [21], and Teng et al. [22]. Recently, Dobson et al. [23] proposed an EOQ inventory model for deteriorating items with a single product in which demand rate of consumers linearly decreased as a function of the age of the product.
Furthermore, EPQ inventory model has been extended by relaxing perfect production systems in different studies. Salameh and Jaber [24] considered an imperfect production system in which poor quality products could be sold at a lower price after $100 \%$ inspection. Afterwards, Goyal and CárdenasBarrón [25] proposed a simpler approach to solving the aforementioned problem with near optimal solutions. Wee et al. [26] generalized Salameh and Jaber [24] by modelling an imperfect production system in an uncompetitive market where shortage was permitted and fully backordered. Haji et al. [27] developed a model and its optimization for an imperfect production system with rework where the machine required setup before starting the rework procedure. Recently, Nobil et al. [28] indicated the possibility of shortage occurrence during setup time in the former models and proposed a modified algorithm to overcome this deficiency. Cárdenas-Barrón [29] studied an imperfect production system with rework and planned backorders. Hsu and Hsu [30], Farhangi et al. [31], CárdenasBarrón et al. [32], Shah et al. [33], Jaggi et al. [34], and Jaggi et al. [35] have presented some recent inventory management instances with imperfect products.

Producing several items on a machine is another realistic extension of EPQ inventory model. Rogers [36] proposed the first instance of this kind of inventory model. Taleizadeh et al. [37] developed the aforementioned model with respect to shortage and imperfect production system with interruptions, scrapped items, and rework. Pasandideh et al. [38] proposed an EPQ inventory model for an imperfect production system with permissible shortage. They considered a machine that produced various quality items, i.e., perfect, scrap, and reworked. They considered diverse failure levels with their own rework procedures. This classification of rework made the inventory model more realistic by considering various types of production error. Nobil et al. [39] considered utilization-allocation policy in an imperfect manufacturing system producing multiple products on several machines using single-machine properties and common cycle length to reduce calculation efforts in a hybrid genetic algorithm. Nobil and Taleizadeh [40], Nobil et al. [41], and Nobil et al. [42] have recently presented some inventory management studies with single-machine production system.

In this study, an imperfect production system with permissible shortages in backorder form is considered. A single machine produces a number of items including unconfirmed products in the form of rework or scrap. Like real-world production systems, there are various kinds of faults leading to various breakdown severity. As a result of diverse breakdown severity, products require different kinds of rework. Moreover, we extend Pasandideh et al. [38] research by considering non-zero setup times for rework as in Haji 
et al. [27]. By relaxing zero setup time, the mentioned problems would be a sub-problem of the current study and the problem becomes closer to real-world instances, in which machines require some preparations before starting a new production cycle. After proving convexity, employing an exact method developed based on the derivatives, the solution procedure for the current nonlinear optimization problem is proposed.

The remainder of this paper is as follows: The problem is defined in Section 2. Section 3 proposes an exact algorithm for this problem. A numerical example is studied in Section 4 to assess efficiency of the proposed algorithm. Finally, the paper is concluded by proposing some future research directions in Section 5.

\section{Problem definition}

In this paper, we address a multi-item single-machine production system with imperfect products. The imperfect products may be categorized into two kinds of deficiency, namely scrap and reworked, i.e., the products that are diagnosed as repairable after inspection process. The expected proportion of produced defective items is known and constant. Moreover, repairable products are categorized in a number of classes based on the severity of defects, which directly influences the rework rate. Item $i(i=1,2, \cdots, m)$ is produced at the rate of $\left(P_{i}\right)$ during regular production periods and $\lambda_{i}$ percent of the products are defective. The deficiency rate $\left(\lambda_{i}\right)$ is divided into $\alpha_{i}$ and $\beta_{i}$ for scrap and reworked items, respectively. In other words, $\lambda_{i}=\alpha_{i}+\beta_{i}$, where $\beta_{i}$ consists in $n$ kinds of rework, i.e., $v_{i}^{j}$ percent of item $i$ products require the rework of type $j$ and $j=1,2, \cdots, n$. Therefore, the total proportion of products $i$ that require rework $\left(\beta_{i}\right)$ can be stated as the sum of $v_{i}^{j}$, i.e., $\beta_{i}=v_{i}^{1}+v_{i}^{2}+\cdots+v_{i}^{n}$ or $\beta_{i}=\sum_{j=1}^{n} v_{i}^{j}$. Thus, we have:

$$
\lambda_{i}=\alpha_{i}+\beta_{i}=\alpha_{i}+v_{i}^{1}+v_{i}^{2}+\cdots+v_{i}^{n} .
$$

Furthermore, in the proposed inventory system, all items are produced by one machine; this property lead to the following equation:

$$
T_{1}=T_{2}=T_{3}=\cdots=T_{m}=T \text {. }
$$

The following notations are employed to model the proposed non-linear single-machine inventory control problem with $m$ kinds of items and $n$ types of rework.

$c_{i} \quad$ Production cost of manufacturing each item kind $i(i=1,2, \cdots, m)$;

$o_{i} \quad$ Inspection costs per item kind $i$ $(i=1,2, \cdots, m)$;

$d_{i} \quad$ Disposal costs per item kind $i$ $(i=1,2, \cdots, m)$; $r_{i}^{j} \quad$ Rework costs for item kind $i$ with fault type $j(i=1,2, \cdots, m) \&$ $(j=1,2, \cdots, n)$;

$h_{i} \quad$ Holding costs per year per item kind $i$ $(i=1,2, \cdots, m)$;

$L_{i} \quad$ Shortage costs per year per item kind $i$ $(i=1,2, \cdots, m)$;

$A_{i} \quad$ Setup costs per regular production cycle to produce item kind $i$ $(i=1,2, \cdots, m)$;

$B_{i} \quad$ Setup costs per rework cycle for all rework types associated with item kind $i(i=1,2, \cdots, m)$;

$t s_{i} \quad$ Setup time per regular production cycle to produce item kind $i$ $(i=1,2, \cdots, m)$;

$G_{i} \quad$ Setup time per rework cycle for all rework types associated with item kind $i(i=1,2, \cdots, m)$;

$P_{i} \quad$ Production rate for item kind $i$ $(i=1,2, \cdots, m)$;

$D_{i} \quad$ Demand rate for item kind $i$ $(i=1,2, \cdots, m)$;

$\alpha_{i} \quad$ Disposal rate of produced item kind $i$ $(i=1,2, \cdots, m)$;

$v_{i}^{j} \quad$ Percentage of produced item kind $i$ that requires rework type $j(i=1,2, \cdots, m$ and $j=1,2, \cdots, n)$;

$\lambda_{i} \quad$ Percentage of produced imperfect product kind $i(i=1,2, \cdots, m)$;

$\theta_{i}^{j} \quad$ Rework rate for rework type $j$ associated with item kind $i$ $(i=1,2, \cdots, m$ and $j=1,2, \cdots, n)$;

$T \quad$ Cycle length;

$N \quad$ Number of cycles in a year;

$Q_{i} \quad$ Quantity of produced item kind $i$ per cycle $(i=1,2, \cdots, m)$;

$S_{i} \quad$ Quantity of shortage for item kind $i$ per cycle $(i=1,2, \cdots, m)$.

A schematic diagram of inventory position for this model is represented in Figure 1. As it is demonstrated in Figure 1, production rate of item $i$ during regular cycle is $\left(P_{i}\right)$ in which $\lambda_{i}$ percent of the products are defective; consequently, production rate of nondefective items of kind $i$ per cycle equals $\left(1-\lambda_{i}\right) P_{i}$. On the other hand, production rate of non-defective items should be more than or equal to the demand rate $\left(D_{i}\right)$. In other words, we have:

$$
\left(1-\lambda_{i}\right) P_{i} \geq D_{i} \quad \text { or } \quad e_{i}=\left(1-\lambda_{i}\right) P_{i}-D_{i} \geq 0 .
$$

After accomplishing the regular production cycle and inspection, scrap items are disposed of and rework 


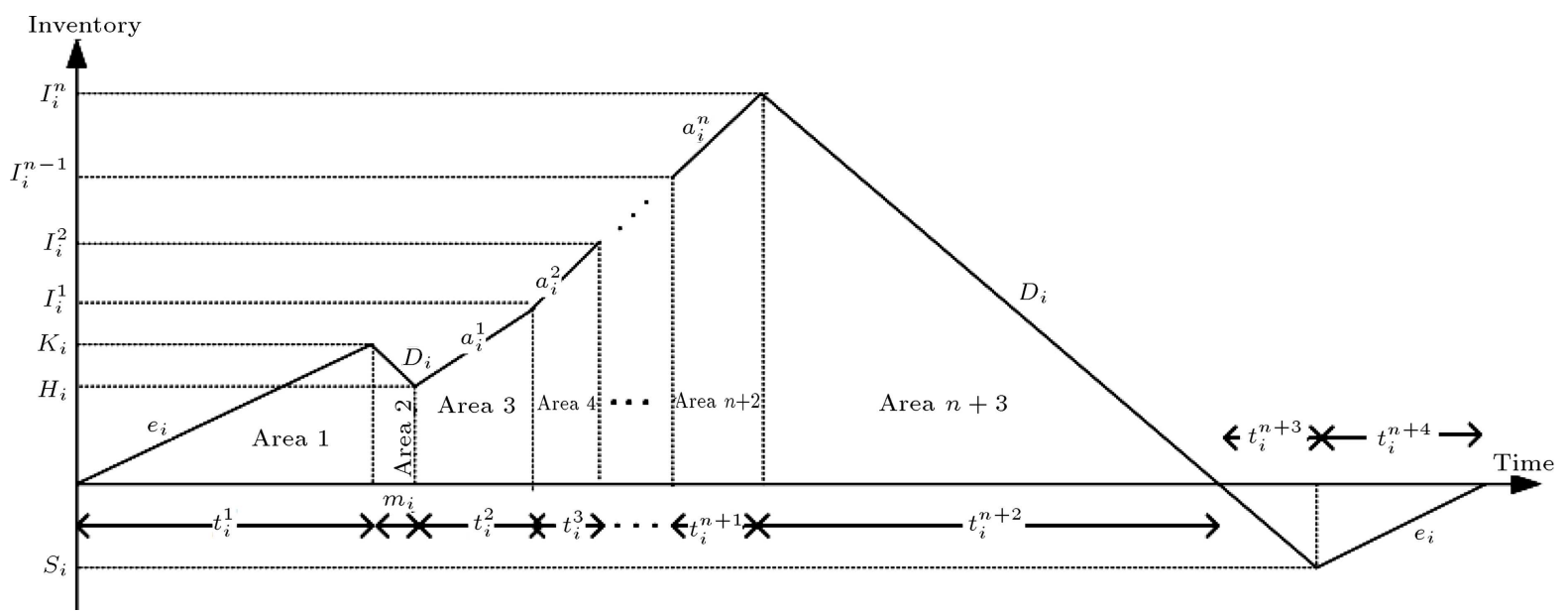

Figure 1. A schematic diagram of inventory level of item $i$.

process should be initiated. In this study, we assume that rework process has a non-zero setup time equal to regular production setup time. Moreover, for the sake of simplicity and as a consequence of independency of setup times, we consider one setup time, namely $G_{i}$, before starting all types of rework for item kind $i$. During setup time, no item is produced and item $i$ is consumed at the rate of $D_{i}$. The rework processes initiate at rates of $\theta_{i}^{1}, \theta_{i}^{2}, \cdots$, and $\theta_{i}^{n}$ during the periods of $t_{i}^{2}, t_{i}^{3}, \cdots$ and $t_{i}^{n+1}$, respectively; during these periods, no scrap item is manufactured. Moreover, it is logical to assume that the rework process of products does not require more time than its corresponding regular production time does. In other words, the rework rate for a product is greater than or equal to its regular production rate, i.e., $\theta_{i}^{j} \geq 1$. Consequently, the demand rate $\left(D_{i}\right)$ for product $i$ is less than or equal to its rework production rate $\theta_{i}^{j} P_{i}$. In other words:

$$
\theta_{i}^{j} P_{i} \geq D_{i} \quad \text { or } \quad a_{i}^{j}=\theta_{i}^{j} P_{i_{i}}-D_{i} \geq 0 .
$$

Based on Figure 1 and the aforementioned conditions, inventory level at the end of each rework process can be stated as:

$$
\begin{aligned}
& K_{i}=\frac{e_{i} Q_{i}}{P_{i}}-S_{i} \\
& H_{i}=K_{i}-G_{i} D_{i}=\frac{e_{i} Q_{i}}{P_{i}}-S_{i}-G_{i} D_{i} \\
& I_{i}^{1}=H_{i}+\frac{a_{i}^{1} v_{i}^{1} Q_{i}}{\theta_{i}^{1} P_{i}}=\frac{e_{i} Q_{i}}{P_{i}}-S_{i}-G_{i} D_{i}+\frac{a_{i}^{1} v_{i}^{1} Q_{i}}{\theta_{i}^{1} P_{i}} \\
& I_{i}^{2}=I_{i}^{1}+\frac{a_{i}^{2} v_{i}^{2} Q_{i}}{\theta_{i}^{2} P_{i}}=\frac{e_{i} Q_{i}}{P_{i}}-S_{i}-G_{i} D_{i}+\frac{a_{i}^{1} v_{i}^{1} Q_{i}}{\theta_{i}^{1} P_{i}} \\
&+\frac{a_{i}^{2} v_{i}^{2} Q_{i}}{\theta_{i}^{2} P_{i}} .
\end{aligned}
$$

Therefore, the following is obtained:

$$
\begin{aligned}
I_{i}^{j} & =\frac{e_{i} Q_{i}}{P_{i}}-S_{i}-G_{i} D_{i}+\left(\sum_{r=1}^{j} \frac{a_{i}^{j} v_{i}^{j} Q_{i}}{\theta_{i}^{j} P_{i}}\right), \\
j & =1,2, \cdots, n .
\end{aligned}
$$

Moreover, based on the inventory level and Figure 1, each period length can be stated as:

$$
\begin{aligned}
& t_{i}^{1}=\frac{K_{i}}{e_{i}}=\frac{Q_{i}}{P_{i}}-\frac{S_{i}}{e_{i}}, \\
& t_{i}^{2}=\frac{I_{i}^{1}-H_{i}}{a_{i}^{1}}=\frac{v_{i}^{1} Q_{i}}{\theta_{i}^{1} P_{i}}, \\
& t_{i}^{3}=\frac{I_{i}^{2}-I_{i}^{1}}{a_{i}^{2}}=\frac{v_{i}^{2} Q_{i}}{\theta_{i}^{2} P_{i}} .
\end{aligned}
$$

Consequently, we have:

$$
t_{i}^{j+1}=\frac{I_{i}^{j}-I_{i}^{j-1}}{a_{i}^{j}}=\frac{v_{i}^{j} Q_{i}}{\theta_{i}^{j} P_{i}}, \quad j=1,2, \cdots, n .
$$

Thus:

$$
t_{i}^{n+1}=\frac{v_{i}^{n} Q_{i}}{\theta_{i}^{n} P_{i}} .
$$

On the other hand, we know that:

$$
\begin{aligned}
t_{i}^{n+2} & =\frac{I_{i}^{n}}{D_{i}}=\frac{e_{i} Q_{i}}{D_{i} P_{i}}-\frac{S_{i}}{D_{i}}-m_{i}+\left(\sum_{r=1}^{j} \frac{a_{i}^{j} v_{i}^{j} Q_{i}}{\theta_{i}^{j} D_{i} P_{i}}\right) \\
t_{i}^{n+3} & =\frac{S_{i}}{D_{i}} \\
t_{i}^{n+4} & =\frac{S_{i}}{e_{i}} .
\end{aligned}
$$

Based on the above-mentioned conditions, a period length can be obtained as: 


$$
\begin{aligned}
T=T_{i}= & t_{i}^{1}+m_{i}+t_{i}^{2}+t_{i}^{3}+\cdots+t_{i}^{n+1}+t_{i}^{n+2} \\
& +t_{i}^{n+3}+t_{i}^{n+4} .
\end{aligned}
$$

Moreover, based on Eq. (A.4) stated in Appendix A, a cycle length can be calculated as:

$$
T=\frac{\left(1-\alpha_{i}\right) Q_{i}}{D_{i}}
$$

and:

$$
Q_{i}=\frac{D_{i} T}{\left(1-\alpha_{i}\right)} .
$$

\subsection{Objective function}

The objective function of the proposed problem is to optimize total inventory costs, including annual setup costs for regular production cycles, annual setup costs for rework, annual production costs, annual inspection costs, annual disposal costs, annual rework costs, annual shortage costs, and annual holding costs. As it was mentioned before, setup cost of regular production cycle for item kind $i$ is $A_{i}$. Moreover, each year consists in $N$ cycles and the sum of annual setup costs $(S C)$ for regular production of all items is stated as:

$$
S C=\sum_{i=1}^{m} N A_{i}=\sum_{i=1}^{m} \frac{A_{i}}{T} .
$$

On the other hand, setup cost of rework associated with item kind $i$ per cycle is $B_{i}$ and a year consists in $N$ cycles. Therefore, the sum of annual setup costs $(U C)$ of rework for all items is as follows:

$$
U C=\sum_{i=1}^{m} N B_{i}=\sum_{i=1}^{m} \frac{B_{i}}{T} .
$$

Production cost per item kind $i$ equals $Q_{i}$. As a result, production cost per cycle can be stated as $c_{i} Q_{i}$ and the total production cost per year $(P C)$ is:

$$
P C=\sum_{i=1}^{m} N c_{i} Q_{i}=\sum_{i=1}^{m} \frac{c_{i} Q_{i}}{T} .
$$

Substituting $Q_{i}$ from Eq. (20) in Eq. (23), we have:

$$
P C=\sum_{i=1}^{m} N c_{i} Q_{i}=\sum_{i=1}^{m} \frac{D_{i} c_{i}}{\left(1-\alpha_{i}\right)} .
$$

Inspection cost per item kind $i$ is $o_{i}$ and production quantity of this kind of item per cycle is $Q_{i}$. Therefore, inspection cost per cycle is $o_{i} Q_{i}$ and annual inspection cost $(I C)$ equals:

$$
I C=\sum_{i=1}^{m} N o_{i} Q_{i}=\sum_{i=1}^{m} \frac{D_{i} o_{i}}{\left(1-\alpha_{i}\right)} .
$$

Disposal cost per item kind $i$ is $d_{i}$ and quantity of produced items requiring disposal per cycle is $\alpha_{i} Q_{i}$. Thus, disposal cost per cycle is $d_{i} \alpha_{i} Q_{i}$ and annual disposal cost $(D C)$ can be stated as:

$$
D C=\sum_{i=1}^{m} N d_{i} \alpha_{i} Q_{i}=\sum_{i=1}^{m} \frac{D_{i} d_{i} \alpha_{i}}{\left(1-\alpha_{i}\right)} .
$$

Rework cost of type $j$ per item kind $i$ is $r_{i}^{j}$ and quantity of the produced items requiring this type of rework per cycle is $v_{i}^{j} Q_{i}$. Thus, rework cost type $j$ per cycle is $r_{i}^{j} v_{i}^{j} Q_{i}$ and annual rework cost $(R C)$ can be stated as:

$$
R C=\sum_{i=1}^{m} \sum_{j=1}^{n} N r_{i}^{j} v_{i}^{j} Q_{i}=\sum_{i=1}^{m} \sum_{j=1}^{n} \frac{D_{i} r_{i}^{j} v_{i}^{j}}{\left(1-\alpha_{i}\right)}
$$

As it can be seen in Figure 1, the backordered demands for item kind $i$ can be stated as $S_{i}\left(t_{i}^{n+3}+\right.$ $\left.t_{i}^{n+4}\right) / 2$. Knowing that annual shortage cost for product kind $i$ is $L_{i}$, annual shortage cost $(B C)$ is:

$$
B C=\sum_{i=1}^{m} \frac{N L_{i} S_{i}\left(t_{i}^{n+3}+t_{i}^{n+4}\right)}{2} .
$$

Substituting $t_{i}^{n+3}$ and $t_{i}^{n+4}$ with Eqs. (16) and (17), respectively, we have:

$$
B C=\sum_{i=1}^{m} \frac{L_{i}\left(e_{i}+D_{i}\right)}{2 D_{i} e_{i}}\left(\frac{\left(S_{i}\right)^{2}}{T}\right) .
$$

Annual holding cost for item kind $i$ is $h_{i}$ and with respect to the area under the curve in Figure 1, annual holding costs $(H C)$ can be stated as:

$$
H C=\sum_{i=1}^{m} N h_{i}\left\{\begin{array}{c}
\frac{K_{i} \times t_{i}^{1}}{2}+\frac{\left(K_{i}+H_{i}\right) G_{i}}{2} \\
+\frac{\left(H_{i}+I_{i}^{1}\right) t_{i}^{2}}{2}+\frac{\left(I_{i}^{1}+I_{i}^{2}\right) t_{i}^{3}}{2} \\
+\cdots+\frac{\left(I_{i}^{n-1}+I_{i}^{n}\right) t_{i}^{n+1}}{2} \\
+\frac{I_{i}^{n} \times t_{i}^{n+2}}{2}
\end{array}\right\}(30)
$$

This equation can be stated as follows. For calculations, see Eq. (B.10) in Appendix B:

$$
\begin{aligned}
H C= & \frac{h_{i} e_{i} G_{i} D_{i}}{P_{i}\left(1-\alpha_{i}\right)}+\frac{h_{i} e_{i}\left(1-\lambda_{i}\right)}{2 P_{i}\left(1-\alpha_{i}\right)^{2}}(T) \\
& +\frac{h_{i} P_{i}\left(1-\lambda_{i}\right)}{2 e_{i} D_{i}}\left(\frac{\left(S_{i}\right)^{2}}{T}\right)-\frac{h_{i} G_{i}}{2}\left(\frac{S_{i}}{T}\right) \\
& -\frac{h_{i} e_{i}}{2 P_{i}\left(1-\alpha_{i}\right)}\left(S_{i}\right) \\
& +\frac{h_{i}\left(D_{i}\right)^{2}}{\left(P_{i}\right)^{2}\left(1-\alpha_{i}\right)^{2}} \sum_{j=1}^{n} \frac{v_{i}^{j}}{\theta_{i}^{j}}\left(\sum_{y=0}^{j-1} \frac{a_{i}^{y} v_{i}^{y}}{\theta_{i}^{y}}\right)(T
\end{aligned}
$$




$$
\begin{aligned}
& -\frac{h_{i} G_{i} D_{i}}{P_{i}\left(1-\alpha_{i}\right)}\left(D_{i} \sum_{j=1}^{n} \frac{v_{i}^{j}}{\theta_{i}^{j}}+\sum_{j=1}^{n} \frac{a_{i}^{j} v_{i}^{j}}{2 \theta_{i}^{j}}\right) \\
& -\frac{h_{i} D_{i}}{P_{i}\left(1-\alpha_{i}\right)}\left(\sum_{j=1}^{n} \frac{v_{i}^{j}}{\theta_{i}^{j}}+\frac{1}{2 D_{i}} \sum_{j=1}^{n} \frac{a_{i}^{j} v_{i}^{j}}{\theta_{i}^{j}}\right)\left(S_{i}\right) \\
& +\frac{h_{i} e_{i}\left(D_{i}\right)^{2}}{\left(P_{i}\right)^{2}\left(1-\alpha_{i}\right)^{2}}\left(\sum_{j=1}^{n} \frac{v_{i}^{j}}{\theta_{i}^{j}}\right. \\
& \left.+\frac{1}{2 D_{i}} \sum_{j=1}^{n} \frac{a_{i}^{j} v_{i}^{j}}{\theta_{i}^{j}}\right)(T) \\
& +\frac{h_{i}\left(D_{i}\right)^{2}}{2\left(P_{i}\right)^{2}\left(1-\alpha_{i}\right)^{2}}\left(\sum_{j=1}^{n} \frac{a_{i}^{j}\left(v_{i}^{j}\right)^{2}}{\left(\theta_{i}^{j}\right)^{2}}\right. \\
& \left.+\frac{1}{D_{i}} \sum_{j=1}^{n}\left(\frac{a_{i}^{j} v_{i}^{j}}{\theta_{i}^{j}}\right)^{2}\right)(T) .
\end{aligned}
$$

Finally, based on Eqs. (21), (22), (24), (25), (26), (27), (29), and (31), the annual total cost can be calculated as follows:

$$
\begin{aligned}
T C= & \sum_{i=1}^{m} \beta_{i}^{1}+\sum_{i=1}^{m} \beta_{i}^{2}(T)+\sum_{i=1}^{m} \frac{\beta_{i}^{3}}{T}-\sum_{i=1}^{m} \beta_{i}^{4}\left(\frac{S_{i}}{T}\right) \\
& -\sum_{i=1}^{m} \beta_{i}^{5} S_{i}+\sum_{i=1}^{m} \beta_{i}^{6}\left(\frac{\left(S_{i}\right)^{2}}{T}\right)
\end{aligned}
$$

where:

$$
\begin{aligned}
\beta_{i}^{1}= & \frac{h_{i} G_{i} D_{i}}{P_{i}\left(1-\alpha_{i}\right)}\left(e_{i}-D_{i} \sum_{j=1}^{n} \frac{v_{i}^{j}}{\theta_{i}^{j}}-\sum_{j=1}^{n} \frac{a_{i}^{j} v_{i}^{j}}{2 \theta_{i}^{j}}\right) \\
& +\frac{D_{i}\left(c_{i}+o_{i}+d_{i} \alpha_{i}+\sum_{j=1}^{n} r_{i}^{j} v_{i}^{j}\right)}{\left(1-\alpha_{i}\right)}, \\
\beta_{i}^{2}= & \frac{h_{i} e_{i}\left(D_{i}\right)^{2}}{\left(P_{i}\right)^{2}\left(1-\alpha_{i}\right)^{2}}\left(\sum_{j=1}^{n} \frac{v_{i}^{j}}{\theta_{i}^{j}}+\frac{1}{2 D_{i}} \sum_{j=1}^{n} \frac{a_{i}^{j} v_{i}^{j}}{\theta_{i}^{j}}\right) \\
& +\frac{h_{i}\left(D_{i}\right)^{2}}{2\left(P_{i}\right)^{2}\left(1-\alpha_{i}\right)^{2}}\left(\sum_{j=1}^{n} \frac{a_{i}^{j}\left(v_{i}^{j}\right)^{2}}{\left(\theta_{i}^{j}\right)^{2}}\right. \\
& \left.+\frac{1}{D_{i}} \sum_{j=1}^{n}\left(\frac{a_{i}^{j} v_{i}^{j}}{\theta_{i}^{j}}\right)^{2}\right) \\
& +\frac{h_{i}\left(D_{i}\right)^{2}}{\left(P_{i}\right)^{2}\left(1-\alpha_{i}\right)^{2}} \sum_{j=1}^{n} \frac{v_{i}^{j}}{\theta_{i}^{j}}\left(\sum_{y=0}^{j-1} \frac{a_{i}^{y} v_{i}^{y}}{\theta_{i}^{y}}\right)
\end{aligned}
$$

$$
\begin{aligned}
& +\frac{h_{i} e_{i}\left(1-\lambda_{i}\right)}{2 P_{i}\left(1-\alpha_{i}\right)^{2}} \geq 0, \quad i=1,2, \cdots, m, \\
\beta_{i}^{3}= & A_{i}+B_{i} \geq 0, \quad i=1,2, \cdots, m, \\
\beta_{i}^{4}= & \frac{h_{i} G_{i}}{2} \geq 0, \quad i=1,2, \cdots, m, \\
\beta_{i}^{5}= & \frac{h_{i} D_{i}}{P_{i}\left(1-\alpha_{i}\right)}\left(\sum_{j=1}^{n} \frac{v_{i}^{j}}{\theta_{i}^{j}}+\frac{1}{2 D_{i}} \sum_{j=1}^{n} \frac{a_{i}^{j} v_{i}^{j}}{\theta_{i}^{j}}\right) \\
& +\frac{h_{i} e_{i}}{2 P_{i}\left(1-\alpha_{i}\right)} \geq 0, \quad i=1,2, \cdots, m, \\
\beta_{i}^{6}= & \frac{L_{i}\left(e_{i}+D_{i}\right)}{2 D_{i} e_{i}}+\frac{h_{i} P_{i}\left(1-\lambda_{i}\right)}{2 e_{i} D_{i}} \geq 0, \\
i= & 1,2, \cdots, m .
\end{aligned}
$$

\subsection{Constraints}

In the proposed problem, the main constraint addresses the production capacity of the machine. This constraint expresses that summation of production times for all items and their setup times should be less than or equal to the permissible production time of the machine. In other words, we have:

$$
\sum_{i=1}^{m}\left(\sum_{j=1}^{n+1} t_{i}^{j}+t_{i}^{n+4}+t s_{i}+G_{i}\right) \leq T .
$$

This constraint can be stated as follows. For detailed calculations, see Inequality (C.4) in Appendix C:

$$
T \geq \frac{\sum_{i=1}^{m}\left(t s_{i}+G_{i}\right)}{1-\sum_{i=1}^{m}\left(\frac{D_{i}}{\left(1-\alpha_{i}\right) P_{i}}\left(1+\sum_{j=1}^{n} \frac{v_{i}^{j}}{\theta_{i}^{j}}\right)\right)} .
$$

Other constraints restrict shortage in rework setup time. In other words, we have $m$ constraints to prepare the machine for rework equal to the number of items. With respect to Figure 1, we have:

$$
H_{i} \geq 0, \quad i=1,2, \cdots, m \text {. }
$$

By employing Eq. (6), the following holds:

$$
\frac{e_{i} Q_{i}}{P_{i}}-S_{i}-G_{i} D_{i} \geq 0, \quad i=1,2, \cdots, m .
$$

Substituting $Q_{i}$ with Eq. (20), we have:

$$
\frac{e_{i} D_{i} T}{\left(1-\alpha_{i}\right) P_{i}}-S_{i}-G_{i} D_{i} \geq 0, \quad i=1,2, \cdots, m
$$

Therefore:

$$
T \geq \frac{\left(1-\alpha_{i}\right)\left(S_{i}+G_{i} D_{i}\right) P_{i}}{e_{i} D_{i}} \geq 0, \quad i=1,2, \cdots, m
$$




\subsection{Final model}

Based on the objective function proposed in Eq. (32) and constraints proposed in Inequalities (40) and (44), the final model of the proposed problem is as follows:

$$
\begin{aligned}
& \operatorname{Min} T C=\sum_{i=1}^{m} \beta_{i}^{1}+\sum_{i=1}^{m} \beta_{i}^{2}(T)+\sum_{i=1}^{m} \frac{\beta_{i}^{3}}{T} \\
& -\sum_{i=1}^{m} \beta_{i}^{4}\left(\frac{S_{i}}{T}\right)-\sum_{i=1}^{m} \beta_{i}^{5} S_{i} \\
& +\sum_{i=1}^{m} \beta_{i}^{6}\left(\frac{\left(S_{i}\right)^{2}}{T}\right) \\
& \text { s.t: } T \geq \frac{\sum_{i=1}^{m}\left(t s_{i}+G_{i}\right)}{1-\sum_{i=1}^{m}\left(\frac{D_{i}}{\left(1-\alpha_{i}\right) P_{i}}\left(1+\sum_{j=1}^{n} \frac{v_{i}^{j}}{\theta_{i}^{j}}\right)\right)} \text {, } \\
& T \geq \frac{\left(1-\alpha_{i}\right)\left(S_{i}+G_{i} D_{i}\right) P_{i}}{e_{i} D_{i}} \geq 0, \\
& i=1,2, \cdots, m, \quad T>0, \\
& S_{i} \geq 0 ; \quad i=1,2, \cdots, m .
\end{aligned}
$$

\section{Solution method}

In this section, we propose a solution method to optimize the proposed non-linear programming model. To do so, first, we prove the convexity of model (45) by investigating the objective function. It is worth mentioning that all decision variables are continuous and constraints are in linear form. As it can be seen in Appendix D, the quadratic form of objective function (45) is semi-positive. Thus, Model (45) is convex and using partial differentials, we can obtain optimum values for decision variables as follows:

$$
\frac{\partial T C}{\partial S_{i}}=-\frac{\beta_{i}^{4}}{T}-\beta_{i}^{5}+\frac{2 \beta_{i}^{6} S_{i}}{T}=0, \quad i=1,2, \cdots, m .
$$

Therefore:

$$
S_{i}=\frac{\beta_{i}^{5} T+\beta_{i}^{4}}{2 \beta_{i}^{6}}, \quad i=1,2, \cdots, m .
$$

Moreover, by differentiating objective function (45) according to $T$, we have:

$$
\begin{aligned}
\frac{\partial T C}{\partial T}= & \sum_{i=1}^{m} \beta_{i}^{2}-\sum_{i=1}^{m} \frac{\beta_{i}^{3}}{T^{2}}+\sum_{i=1}^{m} \beta_{i}^{4}\left(\frac{S_{i}}{T^{2}}\right) \\
& -\sum_{i=1}^{m} \beta_{i}^{6}\left(\frac{\left(S_{i}\right)^{2}}{T^{2}}\right)=0 .
\end{aligned}
$$

Then:

$$
T^{2}=\frac{\sum_{i=1}^{m} \beta_{i}^{3}-\sum_{i=1}^{m} \beta_{i}^{4} S_{i}+\sum_{i=1}^{m} \beta_{i}^{6}\left(S_{i}\right)^{2}}{\sum_{i=1}^{m} \beta_{i}^{2}} .
$$

Substituting $S_{i}$ with Eq. (47), we have:

$$
T=\sqrt{\frac{\sum_{i=1}^{m} \beta_{i}^{3}-\sum_{i=1}^{m}\left(\frac{\left(\beta_{i}^{4}\right)^{2}}{4 \beta_{i}^{6}}\right)}{\sum_{i=1}^{m} \beta_{i}^{2}-\sum_{i=1}^{m}\left(\frac{\left(\beta_{i}^{5}\right)^{2}}{4 \beta_{i}^{6}}\right)}} .
$$

Based on the obtained solutions from Eqs. (47) and (50), optimum values associated with the model can be achieved using the following algorithm:

Step 1: If $\sum_{i=1}^{m}\left(\frac{D_{i}}{\left(1-\alpha_{i}\right) P_{i}}\left(1+\sum_{j=1}^{n} \frac{v_{i}^{j}}{\theta_{i}^{j}}\right)\right)<0$, go to Step 2. Otherwise, the problem is infeasible and go to Step 14;

Step 2: If $\sum_{i=1}^{m} \beta_{i}^{3}-\sum_{i=1}^{m}\left(\frac{\left(\beta_{i}^{4}\right)^{2}}{4 \beta_{i}^{6}}\right)$ and $\sum_{i=1}^{m} \beta_{i}^{2}-$ $\sum_{i=1}^{m}\left(\frac{\left(\beta_{i}^{5}\right)^{2}}{4 \beta_{i}^{6}}\right)$ are simultaneously positive or negative, go to Step 3. Otherwise, the problem is infeasible and go to Step 14;

Step 3: Calculate $T$ from Eq. (50) and go to Step 4; Step 4: Based on the obtained values for $T$, calculate shortage quantities associated with items using Eq. (47) and go to Step 5;

Step 5: If $S_{i} \geq 0$ for all $i=1,2, \cdots, m$, then go to Step 9; else go to Step 6;

Step 6: If $S_{i}<0(i=1,2, \cdots, m)$, calculate $T L_{i}=$ $\frac{-\beta_{i}^{4}}{\beta_{i}^{5}}$; else for $S_{i} \geq 0$, let $T L_{i}=0$ and go to Step 7 ;

Step 7: Calculate $T$ using:

$$
T=\max \left\{T L_{1}, T L_{2}, \cdots, T L_{m}\right\},
$$

then, go to Step 8;

Step 8: Calculate $S_{i}$ for all $i=1,2, \cdots, m$ employing Eq. (47) with respect to $T$; then, go to Step 9;

Step 9: Calculate values of $T_{G}$ and $T_{i}^{X}(i=$ $1,2, \cdots, m)$, employing the following equations:

$$
\begin{aligned}
T_{G} & =\frac{\sum_{i=1}^{m}\left(t s_{i}+G_{i}\right)}{1-\sum_{i=1}^{m}\left(\frac{D_{i}}{\left(1-\alpha_{i}\right) P_{i}}\left(1+\sum_{j=1}^{n} \frac{v_{i}^{j}}{\theta_{i}^{j}}\right)\right)}, \\
T_{i}^{X} & =\frac{\left(1-\alpha_{i}\right)\left(S_{i}+G_{i} D_{i}\right) P_{i}}{e_{i} D_{i}}, \quad i=1,2, \cdots, m .
\end{aligned}
$$

Step 10: Obtain $T_{\min }$ employing: 


$$
T_{\min }=\max \left\{T_{G}, T_{1}^{X}, T_{2}^{X}, \cdots, T_{m}^{X}\right\},
$$

then, go to Step 11;

Step 11: If $T \geq T_{\min }$, then $T^{*}=T$; else $T^{*}=T_{\min }$ and go to Step 12;

Step 12: Calculate $S_{i}$ for all $i=1,2, \cdots, m$ using Eq. (47) and go to Step 13;

Step 13: According to the obtained values for $T^{*}$ and $S_{i}^{*}$, calculate $Q_{i}^{*}$ and $T C^{*}$ using Eqs. (20) and (32);

Step 14: Terminate the algorithm; if it is feasible, show solutions; else show infeasible.

\section{Numerical experiment}

In this section, we propose a numerical example to investigate efficiency of the proposed solution procedure for this model. The numerical example considers a production system consisting of two items produced by a single machine. Table 1 indicates the information associated with parameters of the proposed numerical example and costs of the system are proposed in Table 2.

The percentage of deficient items produced in the

Table 1. Values associated with parameters of the numerical example.

\begin{tabular}{ccc}
\hline Parameter & Item 1 & Item 2 \\
\hline$P_{i}$ & 8000 & 10000 \\
$D_{i}$ & 3000 & 4200 \\
$\alpha_{i}$ & 0.010 & 0.013 \\
$v_{i}^{1}$ & 0.014 & 0.010 \\
$v_{i}^{2}$ & 0.012 & 0.012 \\
$\theta_{i}^{1}$ & 1 & 1.5 \\
$\theta_{i}^{2}$ & 2 & 2 \\
$t s_{i}$ & 0.0013 & 0.0012 \\
$G_{i}$ & 0.0010 & 0.0010 \\
\hline
\end{tabular}

Table 2. Costs associated with the proposed numerical example.

\begin{tabular}{ccc}
\hline Parameter & Item 1 & Item 2 \\
\hline$c_{i}$ & 400 & 420 \\
$o_{i}$ & 10 & 12 \\
$d_{i}$ & 30 & 25 \\
$r_{i}^{1}$ & 45 & 50 \\
$r_{i}^{2}$ & 55 & 60 \\
$L_{i}$ & 8 & 9 \\
$A_{i}$ & 2000 & 2200 \\
$B_{i}$ & 500 & 400 \\
$h_{i}$ & 5 & 6 \\
\hline
\end{tabular}

system can be calculated as follows:

$$
\begin{aligned}
\lambda_{1} & =\alpha_{1}+\beta_{1}=\alpha_{1}+v_{1}^{1}+v_{1}^{2} \\
& =0.010+0.014+0.012=0.036, \\
\lambda_{2} & =\alpha_{2}+\beta_{2}=\alpha_{2}+v_{2}^{1}+v_{2}^{2} \\
& =0.013+0.010+0.012=0.035 .
\end{aligned}
$$

The rest of the model parameters can be calculated as:

$$
\begin{aligned}
e_{1} & =\left(1-\lambda_{1}\right) P_{1}-D_{1}=(1-0.036) 8000-3000 \\
& =4712>0, \\
e_{2} & =\left(1-\lambda_{2}\right) P_{2}-D_{2}=(1-0.035) 10000-42000 \\
& =5450>0, \\
a_{1}^{1} & =\theta_{1}^{1} P_{1}-D_{1}=1 \times 8000-3000=5000>0, \\
a_{1}^{2} & =\theta_{1}^{2} P_{1}-D_{1}=2 \times 8000-3000=13000>0, \\
a_{2}^{1} & =\theta_{2}^{1} P_{2}-D_{2}=1.5 \times 10000-4200=10800>0, \\
a_{2}^{2} & =\theta_{2}^{2} P_{2}-D_{2}=2 \times 10000-4200=15800>0 .
\end{aligned}
$$

Moreover, $\beta_{i}^{j}(j=1, \cdots, 6)$ can be calculated employing Eqs. (33)-(38). The calculated values for $\beta_{i}^{j}$ are proposed in Table 3.

Now, we calculate the optimum solution for the numerical example using the proposed algorithm in Section 3 as follows:

Step 1: Since:

$$
\left\{\sum_{i=1}^{2}\left(\frac{D_{i}}{\left(1-\alpha_{i}\right) P_{i}}\left(1+\sum_{j=1}^{2} \frac{v_{i}^{j}}{\theta_{i}^{j}}\right)\right)=0.8173\right\}<1,
$$

go to Step 2;

Step 2: Since both:

$$
\left\{\sum_{i=1}^{m} \beta_{i}^{3}-\sum_{i=1}^{m}\left(\frac{\left(\beta_{i}^{4}\right)^{2}}{4 \beta_{i}^{6}}\right) \cong 5099.9\right\},
$$

and:

$$
\left\{\sum_{i=1}^{m} \beta_{i}^{2}-\sum_{i=1}^{m}\left(\frac{\left(\beta_{i}^{5}\right)^{2}}{4 \beta_{i}^{6}}\right) \cong 351.67\right\},
$$

are positive, go to Step 3;

Step 3: Calculate $T$ as follows:

$$
T=\sqrt{\frac{\sum_{i=1}^{m} \beta_{i}^{3}-\sum_{i=1}^{m}\left(\frac{\left(\beta_{i}^{4}\right)^{2}}{4 \beta_{i}^{6}}\right)}{\sum_{i=1}^{m} \beta_{i}^{2}-\sum_{i=1}^{m}\left(\frac{\left(\beta_{i}^{5}\right)^{2}}{4 \beta_{i}^{6}}\right)}}=3.80821661358787
$$

and go to Step 4. 
Table 3. Values associated with $\beta_{i}^{j}$ for $i=1,2$ and $j=1, \cdots, 6$.

\begin{tabular}{ccccccc}
\hline Item & $\boldsymbol{\beta}_{\boldsymbol{i}}^{\mathbf{1}}$ & $\boldsymbol{\beta}_{\boldsymbol{i}}^{\mathbf{2}}$ & $\boldsymbol{\beta}_{\boldsymbol{i}}^{\mathbf{3}}$ & $\boldsymbol{\beta}_{\boldsymbol{i}}^{\mathbf{4}}$ & $\boldsymbol{\beta}_{\boldsymbol{i}}^{\mathbf{5}}$ & $\boldsymbol{\beta}_{\boldsymbol{i}}^{\mathbf{6}}$ \\
\hline 1 & 1247251.09469697 & 154.583355014794 & 2500 & 0.0025 & 1.57196969696970 & 40000.0021312960 \\
2 & 1844885.90655319 & 197.079845283519 & 2600 & 0.0030 & 1.73957446808511 & 60000.0018512451 \\
\hline
\end{tabular}

Step 4: Shortage values associated with each item are as follows:

$$
S_{1}=\frac{\beta_{1}^{5} T+\beta_{1}^{4}}{2 \beta_{1}^{6}} \cong 0, \quad S_{2}=\frac{\beta_{2}^{5} T+\beta_{2}^{4}}{2 \beta_{2}^{6}} \cong 0,
$$

go to Step 5;

Step 5: Since $S_{1}=S_{2}=0$, go to Step 9;

Step 9: Obtain the values of $T_{G}, T_{1}^{X}$, and $T_{2}^{X}$ as follows:

$$
\begin{aligned}
T_{G} & =\frac{\sum_{i=1}^{m}\left(t s_{i}+G_{i}\right)}{1-\sum_{i=1}^{m}\left(\frac{D_{i}}{\left(1-\alpha_{i}\right) P_{i}}\left(1+\sum_{j=1}^{n} \frac{v_{i}^{j}}{\theta_{i}^{j}}\right)\right)} \\
& =0.0246286036910265, \\
T_{1}^{X} & =\frac{\left(1-\alpha_{1}\right)\left(S_{1}+G_{1} D_{1}\right) P_{1}}{e_{1} D_{1}} \\
& =0.00168085688321865, \\
T_{2}^{X} & =\frac{\left(1-\alpha_{2}\right)\left(S_{2}+G_{2} D_{2}\right) P_{2}}{e_{2} D_{2}} \\
& =0.00181103298935632,
\end{aligned}
$$

go to Step 10;

Step 10: $T_{\min }$ is obtained as:

$$
T_{\min }=\max \left\{T_{G}, T_{1}^{X}, T_{2}^{X}\right\}=0.0246286036910265,
$$

go to Step 11;

Step 11: Since $T \geq T_{\min }$, we have $T^{*}=T=$ 3.80821661358787; go to Step 12;

Step 12: Obtain $S_{i}^{*}$ with respect to calculated $T^{*}$ as follows:

$$
S_{1}^{*}=\frac{\beta_{1}^{5} T^{*}+\beta_{1}^{4}}{2 \beta_{1}^{6}} \cong 0, \quad S_{2}^{*}=\frac{\beta_{2}^{5} T^{*}+\beta_{2}^{4}}{2 \beta_{2}^{6}} \cong 0,
$$

go to Step 13;

Step 13: Calculate $Q_{i}^{*}$ and $T C^{*}$ based on the $T^{*}$ and $S_{i}^{*}$ obtained in the former steps as follows:

$$
Q_{1}^{*}=\frac{D_{1} T^{*}}{\left(1-\alpha_{1}\right)}=11540.0503442057,
$$

$$
\begin{aligned}
Q_{2}^{*}= & \frac{D_{2} T^{*}}{\left(1-\alpha_{2}\right)}=16205.1770790973 \\
T C^{*}= & \sum_{i=1}^{m} \beta_{i}^{1}+\sum_{i=1}^{m} \beta_{i}^{2}\left(T^{*}\right)+\sum_{i=1}^{m} \frac{\beta_{i}^{3}}{T^{*}} \\
& -\sum_{i=1}^{m} \beta_{i}^{4}\left(\frac{S_{i}^{*}}{T^{*}}\right)-\sum_{i=1}^{m} \beta_{i}^{5} S_{i}^{*} \\
& +\sum_{i=1}^{m} \beta_{i}^{6}\left(\frac{\left(S_{i}^{*}\right)^{2}}{T^{*}}\right)=\$ 3094815.42042686 .
\end{aligned}
$$

\section{Conclusion and suggestions}

In this study, we investigated a defective single-machine manufacturing system for several commodities. The manufactured products may have problems with operator error, raw materials quality, and machine failure. Therefore, a percentage of the production may have a percentage of unacceptable quality. These defective products are identified by $100 \%$ inspection during production, and they are reworked or disposed of after normal production process. Goods that required rework were classified into several categories based on their types of failure, each with a different rework rate. In this system, there was a setup time to manufacture each item on the machine in a normal cycle; in the rework cycle, a new setup time was incurred. This study presented a single-machine lot-sizing problem for an imperfect manufacturing system with scrap and rework under non-zero setup times for rework items. The rework was classified into several categories based on the types of failure and rework rates. Considering the aforementioned conditions and permissible shortage backordered, the proposed problem was modelled as a non-linear programming model. The convexity of this model was proved and an exact algorithm was proposed. Finally, a numerical example was given to assess the effectiveness of the proposed algorithm under different conditions.

\subsection{Managerial insights}

Taking into account the behavioral factors, this study investigates a fairly practical problem. Therefore, this research can provide production managers and planners with insights in their decision-making. The nonlinear lot-sizing model of this research integrates the production decisions, inventory, and rework. Thus, the model provides a good framework for the im- 
perfect manufacturing system with scrap and rework.

\subsection{Limitations and future directions}

This research considers only a deficient manufacturing system with permissible shortages. The production system consists in a single machine that manufactures items with a certain percentage of defective items that can be reworked or thrown away as scrap. For future work, one can consider different marketing and pricing policies with budget and storage space constraints. One can also consider the impact of information sharing between the manufacturer and the end user.

\section{References}

1. Harris, F.W. "How many parts to make at once", Factory, The Magazine of Management, 10(2), pp. 135-136, 152 (1913).

2. Cárdenas-Barrón, L.E., Chung, K.J., and TreviñoGarza, G. "Celebrating a century of the economic order quantity model in honor of Ford Whitman Harris", International Journal of Production Economics, 155, pp. 1-7 (2014).

3. Taft, E.W. "The most economical production lot", Iron Age, 101(18), pp. 1410-1412 (1918).

4. Hadley, G. and Whitin, T.M., Analysis of Inventory Systems, Prentice-Hall, Englewood Cliffs, NJ (1963).

5. Parker, L.L. "Economical reorder quantities and reorder points with uncertain demand", Naval Research Logistics Quarterly, 11(3-4), pp. 351-358 (1964).

6. Yao, J.S. and Lee, H.M. "Fuzzy inventory with backorder for fuzzy order quantity", Information Sciences, 93(3), pp. 283-319 (1996).

7. Lee, H.M. and Yao, J.S. "Economic order quantity in fuzzy sense for inventory without backorder model", Fuzzy Sets and Systems, 105(1), pp. 13-31 (1999).

8. Björk, K.M. "An analytical solution to a fuzzy economic order quantity problem", International Journal of Approximate Reasoning, 50(3), pp. 485-493 (2009).

9. Silver, E. "Establishing the order quantity when the amount received is uncertain", INFOR: Information Systems and Operational Research, 14(1), pp. 32-39 (1976).

10. Maddah, B., and Jaber, M.Y. "Economic order quantity for items with imperfect quality: revisited", International Journal of Production Economics, 112(2), pp. 808-815 (2008).

11. Khan, M., Jaber, M.Y., and Bonney, M. "An economic order quantity (EOQ) for items with imperfect quality and inspection errors", International Journal of Production Economics, 133(1), pp. 113-118 (2011).

12. Whitin, T.M., Theory of Inventory Management, Princeton University Press, Princeton, NJ, USA (1957).
13. Aggarwal, S.P. and Jaggi, C.K. "Ordering policies of deteriorating items under permissible delay in payments", Journal of the Operational Research Society, 46(5), pp. 658-662 (1995).

14. Wu, K.S., Ouyang, L.Y., and Yang, C.T. "An optimal replenishment policy for non-instantaneous deteriorating items with stock-dependent demand and partial backlogging", International Journal of Production Economics, 101(2), pp. 369-384 (2006).

15. Chang, C.T., Teng, J.T., and Goyal, S.K. "Optimal replenishment policies for non-instantaneous deteriorating items with stock-dependent demand", International Journal of Production Economics, 123(1), pp. $62-68$ (2010).

16. Wu, J., Ouyang, L.Y., Cárdenas-Barrón, L.E., and Goyal, S.K. "Optimal credit period and slot size for deteriorating items with expiration dates under twolevel trade credit financing", European Journal of Operational Research, 237(3), pp. 898-908 (2014).

17. Sett, B.K., Sarkar, S., Sarkar, B., and Yun, W.Y. "Optimal replenishment policy with variable deterioration for fixed-lifetime products", Scientia Iranica, Transactions E, Industrial Engineering, 23(5), pp. 2318-2329 (2016).

18. Wu, C.F. and Zhao, Q.H. "An inventory model for deteriorating items with inventory-dependent and linear trend demand under trade credit", Scientia Iranica, Transactions E, Industrial Engineering, 22(6), pp. $2558-2570$ (2015).

19. Mokhtari, H., Naimi-Sadigh, A., and Salmasnia, A. "A computational approach to economic production quantity model for perishable products with backordering shortage and stock-dependent demand", Scientia Iranica, Transactions E, Industrial Engineering, 24(4), pp. 2138-2151 (2017).

20. Wu, J., Al-Khateeb, F.B., Teng, J.T., and CárdenasBarrón, L.E. "Inventory models for deteriorating items with maximum lifetime under downstream partial trade credits to credit-risk customers by discounted cash-flow analysis", International Journal of Production Economics, 171, pp. 105-115 (2016).

21. Shah N.H. and Cárdenas-Barrón, L.E. "Retailer's decision for ordering and credit policies for deteriorating items when a supplier offers order-linked credit period or cash discount", Applied Mathematics and Computation, 259, pp. 569-578 (2015).

22. Teng, J.T., Cárdenas-Barrón, L.E., Chang, H.J., Wu, J., and $\mathrm{Hu}, \mathrm{Y}$. "Inventory lot-size policies for deteriorating items with expiration dates and advance payments", Applied Mathematical Modelling, 40(19), pp. 8605-8616 (2016).

23. Dobson, G., Pinker, E.J., and Yildiz, O. "An EOQ model for perishable goods with age-dependent demand rate", European Journal of Operational Research, 257(1), pp. 84-88 (2017).

24. Salameh, M.K. and Jaber, M.Y. "Economic production quantity model for items with imperfect quality", 
International Journal of Production Economics, 64(1), pp. 59-64 (2000).

25. Goyal, S.K. and Cárdenas-Barrón, L.E. "Note on: economic production quantity model for items with imperfect quality-a practical approach", International Journal of Production Economics, 77(1), pp. 85-87 (2002).

26. Wee, H.M., Yu, J., and Chen, M.C. "Optimal inventory model for items with imperfect quality and shortage backordering", Omega, 35(1), pp. 7-11 (2007).

27. Haji, R., Haji, A., Sajadifar, M., and Zolfaghari, S. "Lot sizing with non-zero setup times for rework", Journal of Systems Science and Systems Engineering, 17(2), pp. 230-240 (2008).

28. Nobil, A.H., Nobil, E., and Cárdenas-Barrón, L.E. "Some observations to: lot sizing with non-zero setup times for rework", International Journal of Applied and Computational Mathematics, 3(1), pp. 1511-1517 (2017).

29. Cárdenas-Barrón, L.E. "Economic production quantity with rework process at a single-stage manufacturing system with planned backorders", Computers \& Industrial Engineering, 57(3), pp. 1105-1113 (2009).

30. Hsu, J.T. and Hsu, L.F. "Two EPQ models with imperfect production processes, inspection errors, planned backorders, and sales returns", Computers \& Industrial Engineering, 64(1), pp. 389-402 (2013).

31. Farhangi, M., Niaki, S.T.A., and Vishkaei, B.M. "Closed-form equations for optimal lot sizing in deterministic EOQ models with exchangeable imperfect quality items", Scientia Iranica, Transactions E, Industrial Engineering, 22(6), pp. 2621-2633 (2015).

32. Cárdenas-Barrón, L.E., Sarkar, B., and Treviño-Garza, G. "Easy and improved algorithms to joint determination of the replenishment lot size and number of shipments for an EPQ model with rework", Mathematical and Computational Applications, 18(2), pp. 132-138 (2013).

33. Shah, N.H., Patel, D.G., and Shah, D.B. "EPQ model for returned/reworked inventories during imperfect production process under price-sensitive stockdependent demand", Operational Research, pp. 1-17 (2016).

34. Jaggi, C.K., Tiwari, S., and Shafi, A. "Effect of deterioration on two-warehouse inventory model with imperfect quality", Computers \& Industrial Engineering, 88, pp. 378-385 (2015).

35. Jaggi, C.K., Cárdenas-Barrón, L.E., Tiwari, S., and Shafi, A.A. "Two-warehouse inventory model for deteriorating items with imperfect quality under the conditions of permissible delay in payments", Scientia Iranica, Transactions E, Industrial Engineering, 24(1), pp. 390-412 (2017).

36. Rogers, J. "A computational approach to the economic lot-scheduling problem", Management Science, 4(3), pp. 264-291 (1958).
37. Taleizadeh, A.A., Cárdenas-Barrón, L.E., and Mohammadi, B. "A deterministic multi product single machine EPQ model with backordering, scraped products, rework and interruption in manufacturing process", International Journal of Production Economics, 150, pp. 9-27 (2014).

38. Pasandideh, S.H.R., Niaki, S.T.A., Nobil, A.H., and Cárdenas-Barrón, L.E. "A multiproduct single machine economic production quantity model for an imperfect production system under warehouse construction cost", International Journal of Production Economics, 169, pp. 203-214 (2015).

39. Nobil, A.H., Sedigh, A.H.A., and Cárdenas-Barrón, L.E. "A multi-machine multi-product EMQ problem for an imperfect manufacturing system considering utilization and allocation decisions", Expert Systems with Applications, 56, pp. 310-319 (2016).

40. Nobil, A.H. and Taleizadeh, A.A. "A single machine EPQ inventory model for a multi-product imperfect production system with rework process and auction", International Journal of Advanced Logistics, 5(3-4), pp. 141-152 (2016).

41. Nobil, A.H., Sedigh, A.H.A., and Cárdenas-Barrón, L.E. "A multiproduct single machine economic production quantity (EPQ) inventory model with discrete delivery order, joint production policy and budget constraints", Annals of Operations Research, pp. 1-37 (2017). doi: 10.1007/s10479-017-2650-9

42. Nobil, A.H., Sedigh, A.H.A., and Cárdenas-Barrón, L.E. "Multi-machine economic production quantity for items with scrapped and rework with shortages and allocation decisions", Scientia Iranica, Transactions E, Industrial Engineering, 25(4), pp. 2331-2346 (2018). doi: $10.24200 /$ sci. 2017.4453

\section{Appendix A}

\section{Calculating cycle length}

Based on Eq. (18), the production cycle length is:

$$
\begin{aligned}
T= & T_{i}=t_{i}^{1}+G_{i}+t_{i}^{2}+t_{i}^{3}+\cdots+t_{i}^{n+1}+t_{i}^{n+2} \\
& +t_{i}^{n+3}+t_{i}^{n+4} .
\end{aligned}
$$

Moreover, based on Eqs. (10) to (17), we have:

$$
\begin{aligned}
T= & \frac{Q_{i}}{P_{i}}-\frac{S_{i}}{e_{i}}+G_{i}+\frac{v_{i}^{1} Q_{i}}{\theta_{i}^{1} P_{i}}+\frac{v_{i}^{2} Q_{i}}{\theta_{i}^{2} P_{i}}+\cdots+\frac{v_{i}^{n} Q_{i}}{\theta_{i}^{n} P_{i}} \\
& +\frac{e_{i} Q_{i}}{D_{i} P_{i}}-\frac{S_{i}}{D_{i}}-G_{i}+\left(\sum_{r=1}^{j} \frac{a_{i}^{j} v_{i}^{j} Q_{i}}{\theta_{i}^{j} D_{i} P_{i}}\right)+\frac{S_{i}}{D_{i}}+\frac{S_{i}}{e_{i}} \\
& =\frac{Q_{i}}{P_{i}}+\frac{e_{i} Q_{i}}{D_{i} P_{i}}+\left(\sum_{r=1}^{j} \frac{v_{i}^{j} Q_{i}}{\theta_{i}^{j} P_{i}}\right)+\left(\sum_{r=1}^{j} \frac{a_{i}^{j} v_{i}^{j} Q_{i}}{\theta_{i}^{j} D_{i} P_{i}}\right) \\
& =\frac{Q_{i}}{P_{i}}\left(1+\frac{e_{i}}{D_{i}}\right)+\frac{Q_{i}}{P_{i}}\left(\sum_{r=1}^{j} \frac{v_{i}^{j}}{\theta_{i}^{j}}+\frac{a_{i}^{j} v_{i}^{j}}{\theta_{i}^{j} D_{i}}\right) .
\end{aligned}
$$


Employing Eqs. (3) and (4), the following holds:

$$
\begin{aligned}
T & =\frac{Q_{i}}{P_{i}}\left(\frac{\left(1-\lambda_{i}\right) P_{i}}{D_{i}}\right)+\frac{Q_{i}}{P_{i}}\left(\sum_{r=1}^{j} \frac{v_{i}^{j} P_{i}}{D_{i}}\right) \\
& =\frac{Q_{i}}{P_{i}}\left(\frac{\left(1-\lambda_{i}\right) P_{i}}{D_{i}}+\sum_{r=1}^{j} \frac{v_{i}^{j} P_{i}}{D_{i}}\right) .
\end{aligned}
$$

Substituting $\lambda_{i}$ from Eq. (1) in Eq. (A.3), we have:

$$
\begin{aligned}
T & =\frac{Q_{i}}{P_{i}}\left(\frac{\left(1-\lambda_{i}\right) P_{i}}{D_{i}}+\sum_{r=1}^{j} \frac{v_{i}^{j} P_{i}}{D_{i}}\right) \\
& =\frac{Q_{i}}{P_{i}}\left(\frac{P_{i}}{D_{i}}-\frac{\alpha_{i} P_{i}}{D_{i}}-\sum_{r=1}^{j} \frac{v_{i}^{j} P_{i}}{D_{i}}+\sum_{r=1}^{j} \frac{v_{i}^{j} P_{i}}{D_{i}}\right) \\
& =\frac{\left(1-\alpha_{i}\right) Q_{i}}{D_{i}} .
\end{aligned}
$$

\section{Appendix B}

\section{Calculating the holding cost}

Based on Eq. (30), the production cycle length is:

$$
H C=\sum_{i=1}^{m} N h_{i}\left\{\begin{array}{l}
\overbrace{\frac{K_{i} \times t_{i}^{1}}{2}+\overbrace{\frac{\left(K_{i}+H_{i}\right) G_{i}}{2}}^{\text {Area 1 }}}^{\text {Area 3 }} \\
+\overbrace{\frac{\left(H_{i}+I_{i}^{1}\right) t_{i}^{2}}{2}+\overbrace{\frac{\left(I_{i}^{1}+I_{i}^{2}\right) t_{i}^{3}}{2}}^{\text {Area } 4}}^{\text {Area } 5} \\
+\overbrace{\frac{\left(I_{i}^{2}+I_{i}^{3}\right) t_{i}^{4}}{2}+\cdots}^{\text {Area } n+2}+\overbrace{(\frac{\left(I_{i}^{n-1}+I_{i}^{n}\right) t_{i}^{n+1}}{2}+\overbrace{\frac{I_{i}^{n} \times t_{i}^{n+2}}{2}}^{\text {Area } n+3}}^{+}
\end{array}\right\} .
$$

Now, we calculate the specified areas in Eq. (B.1) to obtain a general relation for holding costs as follows:

$$
\text { Area } \begin{aligned}
1 & =\frac{K_{i} \times t_{i}^{1}}{2}=\frac{1}{2}\left(\frac{e_{i} Q_{i}}{P_{i}}-S_{i}\right)\left(\frac{Q_{i}}{P_{i}}-\frac{S_{i}}{e_{i}}\right) \\
& =\frac{e_{i}\left(Q_{i}\right)^{2}}{2\left(P_{i}\right)^{2}}-\frac{Q_{i} S_{i}}{P_{i}}+\frac{\left(S_{i}\right)^{2}}{2 e_{i}},
\end{aligned}
$$

Area $2=\frac{\left(K_{i}+H_{i}\right) G_{i}}{2}=\frac{e_{i} G_{i} Q_{i}}{P_{i}}-G_{i} S_{i}-\frac{D_{i}\left(G_{i}\right)^{2}}{2}$

Area $3=\frac{\left(H_{i}+I_{i}^{1}\right) t_{i}^{2}}{2}=\frac{e_{i}\left(Q_{i}\right)^{2}}{2\left(P_{i}\right)^{2}}\left(\frac{v_{i}^{1}}{\theta_{i}^{1}}\right)-\frac{Q_{i} S_{i}}{P_{i}}\left(\frac{v_{i}^{1}}{\theta_{i}^{1}}\right)$

$$
\begin{gathered}
-\frac{D_{i} G_{i} Q_{i}}{P_{i}}\left(\frac{v_{i}^{1}}{\theta_{i}^{1}}\right)+\frac{\left(Q_{i}\right)^{2}}{2\left(P_{i}\right)^{2}}\left(\frac{a_{i}^{1}\left(v_{i}^{1}\right)^{2}}{\left(\theta_{i}^{1}\right)^{2}}\right), \quad(\mathrm{B} .4) \\
\text { Area } 4=\frac{\left(I_{i}^{1}+I_{i}^{2}\right) t_{i}^{3}}{2}=\frac{e_{i}\left(Q_{i}\right)^{2}}{2\left(P_{i}\right)^{2}}\left(\frac{v_{i}^{2}}{\theta_{i}^{2}}\right)-\frac{Q_{i} S_{i}}{P_{i}}\left(\frac{v_{i}^{2}}{\theta_{i}^{2}}\right) \\
-\frac{D_{i} G_{i} Q_{i}}{P_{i}}\left(\frac{v_{i}^{2}}{\theta_{i}^{2}}\right)+\frac{\left(Q_{i}\right)^{2}}{2\left(P_{i}\right)^{2}}\left(\frac{a_{i}^{2}\left(v_{i}^{2}\right)^{2}}{\left(\theta_{i}^{2}\right)^{2}}\right) \\
+\frac{\left(Q_{i}\right)^{2}}{\left(P_{i}\right)^{2}}\left(\frac{a_{i}^{1} v_{i}^{1} v_{i}^{2}}{\theta_{i}^{1} \theta_{i}^{2}}\right), \\
\text { Area } 5=\frac{\left(I_{i}^{2}+I_{i}^{3}\right) t_{i}^{4}}{2}=\frac{e_{i}\left(Q_{i}\right)^{2}}{2\left(P_{i}\right)^{2}}\left(\frac{v_{i}^{3}}{\theta_{i}^{3}}\right)-\frac{Q_{i} S_{i}}{P_{i}}\left(\frac{v_{i}^{3}}{\theta_{i}^{3}}\right) \\
\\
\quad-\frac{D_{i} G_{i} Q_{i}}{P_{i}}\left(\frac{v_{i}^{3}}{\theta_{i}^{3}}\right)+\frac{\left(Q_{i}\right)^{2}}{2\left(P_{i}\right)^{2}}\left(\frac{a_{i}^{3}\left(v_{i}^{3}\right)^{2}}{\left(\theta_{i}^{3}\right)^{2}}\right) \\
+\frac{\left(Q_{i}\right)^{2}}{\left(P_{i}\right)^{2}}\left(\frac{a_{i}^{1} v_{i}^{1} v_{i}^{3}}{\theta_{i}^{1} \theta_{i}^{3}}\right)+\frac{\left(Q_{i}\right)^{2}}{\left(P_{i}\right)^{2}}\left(\frac{a_{i}^{2} v_{i}^{2} v_{i}^{3}}{\theta_{i}^{2} \theta_{i}^{3}}\right) .
\end{gathered}
$$

The areas $(5)$ to $(n+2)$ can be stated as follows:

$$
\begin{aligned}
\text { Area } j+2= & \frac{\left(I_{i}^{j-1}+I_{i}^{j}\right) t_{i}^{j+1}}{2}=\frac{e_{i}\left(Q_{i}\right)^{2}}{2\left(P_{i}\right)^{2}}\left(\frac{v_{i}^{j}}{\theta_{i}^{j}}\right) \\
& -\frac{Q_{i} S_{i}}{P_{i}}\left(\frac{v_{i}^{j}}{\theta_{i}^{j}}\right)-\frac{D_{i} G_{i} Q_{i}}{P_{i}}\left(\frac{v_{i}^{j}}{\theta_{i}^{j}}\right) \\
& +\frac{\left(Q_{i}\right)^{2}}{2\left(P_{i}\right)^{2}}\left(\frac{a_{i}^{j}\left(v_{i}^{j}\right)^{2}}{\left(\theta_{i}^{j}\right)^{2}}\right) \\
& +\frac{\left(Q_{i}\right)^{2}}{\left(P_{i}\right)^{2}}\left(\frac{v_{i}^{j}}{\theta_{i}^{j}}\right) \sum_{y=0}^{j-1}\left(\frac{a_{i}^{y} v_{i}^{y}}{\theta_{i}^{y}}\right), \\
j=1,2, \cdots, &
\end{aligned}
$$

On the other hand, we have:

$$
\begin{aligned}
\text { Area } n+3= & \frac{I_{i}^{n} \times t_{i}^{n+2}}{2}=\frac{I_{i}^{n} \times I_{i}^{n}}{2 D_{i}} \\
= & \frac{1}{2 D_{i}}\left[\frac{e_{i} Q_{i}}{P_{i}}-S_{i}-G_{i} D_{i}\right. \\
& \left.+\left(\sum_{r=1}^{j} \frac{a_{i}^{j} v_{i}^{j} Q_{i}}{\theta_{i}^{j} P_{i}}\right)\right]^{2} .
\end{aligned}
$$

Finally, annual holding costs with respect to Eqs. (B.2) to (B.8) are as follows:

$$
H C=\sum_{i=1}^{m} \frac{h_{i}}{T}\left\{\frac{e_{i} G_{i} Q_{i}}{P_{i}}+\frac{e_{i}\left(1-\lambda_{i}\right)\left(Q_{i}\right)^{2}}{2 P_{i} D_{i}}\right.
$$




$$
\begin{aligned}
& +\frac{P_{i}\left(1-\lambda_{i}\right)\left(S_{i}\right)^{2}}{2 e_{i} D_{i}}-\frac{G_{i} S_{i}}{2}-\frac{e_{i} S_{i} Q_{i}}{2 P_{i} D_{i}} \\
& +\frac{\left(Q_{i}\right)^{2}}{\left(P_{i}\right)^{2}} \sum_{j=1}^{n} \frac{v_{i}^{j}}{\theta_{i}^{j}}\left(\sum_{y=0}^{j-1} \frac{a_{i}^{y} v_{i}^{y}}{\theta_{i}^{y}}\right) \\
& -\frac{G_{i} Q_{i}}{P_{i}}\left(D_{i} \sum_{j=1}^{n} \frac{v_{i}^{j}}{\theta_{i}^{j}}+\sum_{j=1}^{n} \frac{a_{i}^{j} v_{i}^{j}}{2 \theta_{i}^{j}}\right) \\
& -\frac{S_{i} Q_{i}}{P_{i}}\left(\sum_{j=1}^{n} \frac{v_{i}^{j}}{\theta_{i}^{j}}+\frac{1}{2 D_{i}} \sum_{j=1}^{n} \frac{a_{i}^{j} v_{i}^{j}}{\theta_{i}^{j}}\right) \\
& +\frac{e_{i}\left(Q_{i}\right)^{2}}{\left(P_{i}\right)^{2}}\left(\sum_{j=1}^{n} \frac{v_{i}^{j}}{\theta_{i}^{j}}+\frac{1}{2 D_{i}} \sum_{j=1}^{n} \frac{a_{i}^{j} v_{i}^{j}}{\theta_{i}^{j}}\right) \\
& \left.+\frac{\left(Q_{i}\right)^{2}}{2\left(P_{i}\right)^{2}}\left(\sum_{j=1}^{n} \frac{a_{i}^{j}\left(v_{i}^{j}\right)^{2}}{\left(\theta_{i}^{j}\right)^{2}}+\frac{1}{D_{i}} \sum_{j=1}^{n}\left(\frac{a_{i}^{j} v_{i}^{j}}{\theta_{i}^{j}}\right)^{2}\right)\right\} .
\end{aligned}
$$

Moreover, substituting $Q_{i}$ from Eq. (20) in Eq. (B.9), we have:

$$
\begin{aligned}
& H C= \frac{h_{i} e_{i} G_{i} D_{i}}{P_{i}\left(1-\alpha_{i}\right)}+\frac{h_{i} e_{i}\left(1-\lambda_{i}\right)}{2 P_{i}\left(1-\alpha_{i}\right)^{2}}(T) \\
&+\frac{h_{i} P_{i}\left(1-\lambda_{i}\right)}{2 e_{i} D_{i}}\left(\frac{\left(S_{i}\right)^{2}}{T}\right)-\frac{h_{i} G_{i}}{2}\left(\frac{S_{i}}{T}\right) \\
&-\frac{h_{i} e_{i}}{2 P_{i}\left(1-\alpha_{i}\right)}\left(S_{i}\right) \\
&+\frac{h_{i}\left(D_{i}\right)^{2}}{\left(P_{i}\right)^{2}\left(1-\alpha_{i}\right)^{2}} \sum_{j=1}^{n} \frac{v_{i}^{j}}{\theta_{i}^{j}}\left(\sum_{y=0}^{j-1} \frac{a_{i}^{y} v_{i}^{y}}{\theta_{i}^{y}}\right)(T) \\
&-\frac{h_{i} G_{i} D_{i}}{P_{i}\left(1-\alpha_{i}\right)}\left(D_{i} \sum_{j=1}^{n} \frac{v_{i}^{j}}{\theta_{i}^{j}}+\sum_{j=1}^{n} \frac{a_{i}^{j} v_{i}^{j}}{2 \theta_{i}^{j}}\right) \\
&-\frac{h_{i} D_{i}}{P_{i}\left(1-\alpha_{i}\right)}\left(\sum_{j=1}^{n} \frac{v_{i}^{j}}{\theta_{i}^{j}}+\frac{1}{2 D_{i}} \sum_{j=1}^{n} \frac{a_{i}^{j} v_{i}^{j}}{\theta_{i}^{j}}\right)\left(S_{i}\right) \\
&+\frac{h_{i} e_{i}\left(D_{i}\right)^{2}}{\left(P_{i}\right)^{2}\left(1-\alpha_{i}\right)^{2}}\left(\sum_{j=1}^{n} \frac{v_{i}^{j}}{\theta_{i}^{j}}+\frac{1}{2 D_{i}} \sum_{j=1}^{n} \frac{a_{i}^{j} v_{i}^{j}}{\theta_{i}^{j}}\right) \\
&+\frac{h_{i}\left(D_{i}\right)^{2}}{2\left(P_{i}\right)^{2}\left(1-\alpha_{i}\right)^{2}}\left(\sum_{j=1}^{n} \frac{a_{i}^{j}\left(v_{i}^{j}\right)^{2}}{\left(\theta_{i}^{j}\right)^{2}}\right. \\
&\left.+\frac{1}{D_{i}} \sum_{j=1}^{n}\left(\frac{a_{i}^{j} v_{i}^{j}}{\theta_{i}^{j}}\right)^{2}\right)(T) . \\
&(\mathrm{B} .
\end{aligned}
$$

\section{Appendix C}

\section{Calculating production capacity}

Based on Inequality (39), the production capacity is:

$$
\sum_{i=1}^{m}\left(\sum_{j=1}^{n+1} t_{i}^{j}+t_{i}^{n+4}+t s_{i}+G_{i}\right) \leq T .
$$

By employing Eqs. (10)-(14) and (17), the following holds:

$$
\sum_{i=1}^{m}\left(\frac{Q_{i}}{P_{i}}-\frac{S_{i}}{e_{i}}+\sum_{j=1}^{n+1} \frac{v_{i}^{j} Q_{i}}{\theta_{i}^{j} P_{i}}+\frac{S_{i}}{e_{i}}+t s_{i}+G_{i}\right) \leq T .
$$

Moreover, substituting $Q_{i}$ from Eq. (20) in Eq. (C.2), we have:

$$
\sum_{i=1}^{m}\left(\frac{D_{i} T}{\left(1-\alpha_{i}\right) P_{i}}+\sum_{j=1}^{n+1} \frac{v_{i}^{j} D_{i} T}{\theta_{i}^{j}\left(1-\alpha_{i}\right) P_{i}}+t s_{i}+G_{i}\right) \leq T \text {. C. } 3 \text {. }
$$

Therefore:

$$
T \geq \frac{\sum_{i=1}^{m}\left(t s_{i}+G_{i}\right)}{1-\sum_{i=1}^{m}\left(\frac{D_{i}}{\left(1-\alpha_{i}\right) P_{i}}\left(1+\sum_{j=1}^{n} \frac{v_{i}^{j}}{\theta_{i}^{j}}\right)\right)} .
$$

\section{Appendix D}

\section{Calculating quadratic form of objective}

function (45)

Based on objective function (45):

$$
\begin{aligned}
T C= & \sum_{i=1}^{m} \beta_{i}^{1}+\sum_{i=1}^{m} \beta_{i}^{2}(T)+\sum_{i=1}^{m} \frac{\beta_{i}^{3}}{T} \\
& -\sum_{i=1}^{m} \beta_{i}^{4}\left(\frac{S_{i}}{T}\right)-\sum_{i=1}^{m} \beta_{i}^{5} S_{i}+\sum_{i=1}^{m} \beta_{i}^{6}\left(\frac{\left(S_{i}\right)^{2}}{T}\right)_{(\mathrm{D}}
\end{aligned}
$$

The partial derivatives of the objective function are equal to:

$$
\begin{aligned}
\frac{\partial T C}{\partial T}= & \sum_{i=1}^{m} \beta_{i}^{2}-\sum_{i=1}^{m} \frac{\beta_{i}^{3}}{T^{2}}+\sum_{i=1}^{m} \beta_{i}^{4}\left(\frac{S_{i}}{T^{2}}\right) \\
& -\sum_{i=1}^{m} \beta_{i}^{6}\left(\frac{\left(S_{i}\right)^{2}}{T^{2}}\right) \\
\frac{\partial^{2} T C}{\partial^{2} T}= & \frac{2 \sum_{i=1}^{m} \beta_{i}^{3}-2 \sum_{i=1}^{m} \beta_{i}^{4} S_{i}+2 \sum_{i=1}^{m} \beta_{i}^{6}\left(S_{i}\right)^{2}}{T^{3}} \\
\frac{\partial T C}{\partial S_{i}}= & -\frac{\beta_{i}^{4}}{T}+\beta_{i}^{5}+\frac{2 \beta_{i}^{6} S_{i}}{T} \\
\frac{\partial^{2} T C}{\partial^{2} S_{i}}= & \frac{2 \beta_{i}^{6}}{T}
\end{aligned}
$$




$$
\begin{aligned}
& \frac{\partial^{2} T C}{\partial T \partial S_{i}}=\frac{\partial^{2} T C}{\partial S_{i} \partial T}=\frac{\beta_{i}^{4}-2 \beta_{i}^{6} S_{i}}{T^{2}}, \\
& \frac{\partial^{2} T C}{\partial S_{k} \partial S_{i}}=\frac{\partial^{2} T C}{\partial S_{i} \partial S_{k}}=0 .
\end{aligned}
$$

The Hessian matrix of the objective function equals:

$$
\text { Hessian }=\left[\begin{array}{cccc}
\frac{\partial^{2} T C}{\partial{ }^{2} T} & \frac{\partial^{2} T C}{\partial S_{1} \partial T} & \frac{\partial^{2} T C}{\partial S_{2} \partial T} & \frac{\partial^{2} T C}{\partial S_{m} \partial T} \\
\frac{\partial^{2} T C}{\partial T \partial S_{1}} & \frac{\partial^{2} T C}{\partial^{2} S_{1}} & \frac{\partial^{2} T C}{\partial S_{2} \partial S_{1}} & \frac{\partial^{2} T C}{\partial S_{m} \partial S_{1}} \\
\frac{\partial^{2} T C}{\partial T \partial S_{2}} & \frac{\partial^{2} T C}{\partial S_{1} \partial S_{2}} & \frac{\partial^{2} T C}{\partial^{2} S_{2}} & \frac{\partial^{2} T C}{\partial S_{m} \partial S_{2}} \\
\vdots & & & \vdots \\
\frac{\partial^{2} T C}{\partial T \partial S_{m}} & \frac{\partial^{2} T C}{\partial S_{1} \partial S_{m}} & \frac{\partial^{2} T C}{\partial S_{2} \partial S_{m}} & \frac{\partial^{2} T C}{\partial^{2} S_{m}}
\end{array}\right] \text { (D.8) }
$$

Using (D.2) to (D.7), we have:

$$
\begin{aligned}
& \text { Hessian }=\left[\begin{array}{cc}
\frac{2 \sum_{i=1}^{m} \beta_{i}^{3}-2 \sum_{i=1}^{m} \beta_{i}^{4} S_{i}+2 \sum_{i=1}^{m} \beta_{i}^{6}\left(S_{i}\right)^{2}}{T^{3}} & \frac{\beta_{1}^{4}-2 \beta_{1}^{6} S_{1}}{T^{2}} \\
\frac{\beta_{1}^{4}-2 \beta_{1}^{6} S_{1}}{T^{2}} & \frac{2 \beta_{1}^{6}}{T} \\
\frac{\beta_{2}^{4}-2 \beta_{2}^{6} S_{2}}{T^{2}} & 0 \\
\vdots & \vdots \\
\frac{\beta_{m}^{4}-2 \beta_{m}^{6} S_{m}}{T^{2}} & 0
\end{array}\right. \\
& \left.\begin{array}{ccc}
\frac{\beta_{2}^{4}-2 \beta_{2}^{6} S_{2}}{T^{2}} & \cdots & \frac{\beta_{m}^{4}-2 \beta_{m}^{6} S_{m}}{T^{2}} \\
0 & \cdots & 0 \\
\frac{2 \beta_{2}^{6}}{T} & \cdots & 0 \\
\vdots & & \vdots \\
0 & \cdots & \frac{2 \beta_{m}^{6}}{T}
\end{array}\right] .
\end{aligned}
$$

The quadratic form of the objective function is equal to:

$$
\text { Quadratic }=\left[T, S_{1}, S_{2}, \cdots, S_{m}\right](\text { Hessian })\left[\begin{array}{c}
T \\
S_{1} \\
S_{2} \\
\vdots \\
S_{m}
\end{array}\right](\dot{D} .10)
$$

Substituting Hessian from Eq. (D.9) in Eq. (D.10), we have:

$$
\text { Quadratic }=\frac{2 \sum_{i=1}^{m} \beta_{i}^{3}}{T} \geq 0 .
$$

Since $\beta_{i}^{3} \geq 0$ for $i=1,2, \cdots, m$, the quadratic form of the objective function is semi-positive.

\section{Biographies}

Amir Hossein Nobil is currently a PhD candidate in Industrial Engineering at Qazvin Islamic Azad University, Qazvin, Iran. Also, he received both his BSc and MSc degrees in Industrial Engineering from Qazvin Islamic Azad University, Qazvin, Iran. His research interests include supply chain management, inventory control, and production planning.

Amir Hosein Afshar Sedigh is currently a PhD candidate in Information Science at University of Otago, Dunedin, New Zealand. He received a BSc degree from Qazvin Islamic Azad University, Qazvin, Iran, in Industrial Engineering. Thereafter, he received his MSc degree in Industrial Engineering from Sharif University of Technology, Tehran, Iran. His research interests include supply chain management, inventory control, and queuing theory.

Sunil Tiwari is a Post-doctoral Research Fellow in The Logistics Institute-Asia Pacific, National University of Singapore, Singapore. Prior to joining National University of Singapore, he was an Assistant Professor in the Department of Mathematics, Ambedkar University, Delhi. He received his $\mathrm{PhD}$ degree in 2016, MPhil in 2013, and MSc degree in 2011 from the University of Delhi. His research areas are primarily related to inventory control, logistics, and supply chain. He has published research papers in International Journal of Production Economics, Computers and Industrial Engineering, Annals of Operations Research, Neural Computing and Applications, European Journal of Industrial Engineering, RAIROOperations Research, Applied Mathematics and Information Sciences, International Journal of Operational Research, International Journal of Logistics Systems and Management, and International Journal of Industrial Engineering Computations in the mentioned areas.

Hui-Ming Wee is a Distinguished Professor of Industrial and Systems Engineering at the Chung Yuan Christian University in Taiwan. He received his ME in Industrial Engineering and Management from the Asian Institute of Technology and $\mathrm{PhD}$ in Industrial Engineering from the Cleveland State University, Ohio, USA. His research interests are in the fields of production/inventory control, optimization, logistics, renewable energy, and supply chain risk management. He has been a visiting professor to the Asian Institute of Technology, University of Washington, Curtin University of Science and Technology, San Jose State University, University of Technology Sydney, and Colorado State University. 